
(NSN)

\title{
Melatonin and Magnesium Restores Neurohistopathological Changes in the Hippocampus of Streptozotocin-Induced Diabetic Rats
}

\author{
Elvis T. Godam ${ }^{1}$, Wilson O. Hamman ${ }^{2}$, Sunday Oladele ${ }^{3}$, \\ Modupeola O. Samaila ${ }^{4}$ and Sunday A. Musa ${ }^{2}$
}

\begin{abstract}
${ }^{1}$ Department of Human Anatomy, Faculty of Basic Medical Sciences, College of Medical Sciences, Rivers State University, Port Harcourt, Nigeria; ${ }^{2}$ Department of Human Anatomy, Faculty of Basic Medical Sciences, Ahmadu Bello University, Zaria, Nigeria; ${ }^{3}$ Department of Veterinary Pathology, Faculty of Veterinary Medicine, Ahmadu Bello University, Zaria; Nigeria; ${ }^{4}$ Department of Pathology, Faculty of Basic Clinical Sciences, Ahmadu Bello University, Zaria, Nigeria
\end{abstract}

Received: July 2020

Accepted: September 2020

\begin{abstract}
Diabetic encephalopathy and its associated end organ damage have become a major global epidemic in many patients with diabetes mellitus. These diseased conditions are complex and poorly understood, therefore the need to seek for alternative management measures to attenuate the complications associated with it. The aim of this study was to evaluate the effects of co-administration of melatonin and magnesium on the cytoarchitecture of the hippocampus of streptozotocin (STZ) induced diabetic rats. STZ was used to induce type 1 diabetes mellitus. Fifty four rats: Forty eight diabetic and six normoglycaemic rats distributed in nine groups as follow; normal control, diabetic control (DC), melatonin low dose (MLD, $10 \mathrm{mg} / \mathrm{kg}$ ), magnesium low dose (MgLD, $240 \mathrm{mg} / \mathrm{kg}$ ), melatonin and magnesium combined dose (MMgLD, $10 \mathrm{mg} / \mathrm{kg}+240 \mathrm{mg} / \mathrm{kg}$, respectively), melatonin high dose (MHD, $20 \mathrm{mg} / \mathrm{kg}$ ), magnesium high dose (MgHD, $480 \mathrm{mg} / \mathrm{kg}$ ), melatonin and magnesium high dose (MMgHD, $20 \mathrm{mg} / \mathrm{kg}+480 \mathrm{mg} / \mathrm{kg}$, respectively) and insulin (IN, $500 \mathrm{mg} / \mathrm{kg}$ ). Melatonin and insulin were administered through intraperitoneal injections while magnesium was orally. The control groups were given placebo and all treatments were for twenty-one days. Results showed distortion of hippocampal CA1 area in the diabetic control, MgLD, MgHD, MMgHD and IN groups. MLD, MHD and MMgLD groups showed organized structures of hippocampus CA1 area with no cellular distortions, while there were less positive GFAP in the MLD, MHD and MMgLD groups. The DC, MgLD. MgHD, MMgHD and IN groups showed strong GFAP reactivity. In conclusion, MLD, MHD and MMgLD increased neuroprotection of hippocampal neurocytes.
\end{abstract}

Key words: Diabetes; Hippocampus; Astrocytes; Melatonin; Magnesium; Neuroprotection

\section{INTRODUCTION}

Reports published by the World Health Organization (WHO) states that diabetes mellitus (DM) is a common disease with a global prevalence estimated to be $9 \%$ among adults aged 18 years and above (Bytzer et al. 2001). Population-based studies of neuropathy (inflammation and degeneration of peripheral nerves) in persons with diabetes indicates common complications of insulin-dependent diabetes mellitus and non-insulin- dependent diabetes mellitus, with $60 \%-70 \%$ of patients affected with the disease (Ricci et al. 2000). Subclinical neuropathy is much more common than clinical neuropathy. Distal symmetrical polyneuropathy is the most common type of neuropathy, followed by carpal tunnel syndrome, mononeuropathies and autonomic

Correspondence: Elvis T. Godam, MSc, Department of Human Anatomy, Faculty of Basic Medical Sciences, Rivers State University, PMB 5080, Port Harcourt, Nigeria. Email: elvis.godam@ust.edu.ng; Phone: +2348063339602 
neuropathy (Bytzer et al. 2001).

Behavioural and cognitive changes associated with type 1 diabetes mellitus (T1DM) has gained worldwide attention. Concerns about the deleterious effects of T1DM on the central nervous system have grown with the increasing incidence of T1DM in children (Adeghate et al. 2006). Many studies have clearly shown cognitive and behavioural changes in type 1 diabetic rats and humans, which are evident in elevated levels of anxiety, depression, and slowing of mental speed and flexibility (Ramanathan et al. 1998; Brands et al. 2005; Kuhad et al. 2007; Alvarez et al. 2009).

Diabetes-induced behavioural and cognitive changes are related to several factors. Both diabetic complications and reduced central serotonin (5hydroxytryptamine, 5-HT) synthesis and metabolism are thought to underlie behavioural and cognitive dysfunctions in patients with T1DM (Ryan and William 1993; Thorre et al. 1997). It has become evident that insulin and C-peptide deficiencies, including perturbations of their signalling cascades, leads to cerebral dysmetabolism and interference with the regulation of neurotropic factors and their receptors. Ultimately, this cascade of events leads to neuronal loss, causing profound deficits in behavioural and cognitive functions (Sima et al. 2009). However, the specific mechanisms underlying these changes and whether they relate to the duration of diabetes are unknown. Although the magnitude of most of these cognitive decrements is relatively modest, even moderate behavioural and cognitive changes can potentially hamper the day-today activities of both diabetic child and adult. These cognitive decrements may present problems in more demanding situations, and can critically have a negative impact on the quality of life (Sima et al. 2009).

There are many studies on this subject but none has co-administered melatonin and magnesium to ameliorate hyperglycaemia, and neuropathological changes associated with streptozotocin (STZ)induced diabetic rats.

\section{MATERIALS AND METHODS}

\section{Materials}

Plastic cages, standard rat feed, organ sample containers, centrifuge, temperature controlled refrigerator, microwave oven, water bath, humidity chamber, Leica auto processor, Leica auto stainer, Leica DM750, camera ICC50 E, AmScope D200 digital camera, MRC spectrophotometer, HP 8TH gen intel@ CoreTH i5 processor. melatonin M5250-1G (Sigma Aldrich, USA), magnesium (Randox, USA), streptozotocin (SP0130, Sigma Aldrich, USA), haematoxylin and eosin (H\&E), and glial fibrillary acidic protein (GFAP) antibody (Abcam, USA) were used in the study.

\section{Source of Animals and Management}

Sixty four Normoglycaemic rats were weighing 120$150 \mathrm{~g}$, were obtained from the Faculty of Pharmaceutical Sciences Animal House of the Ahmadu Bello University, Zaria for the study. The rats were maintained on ad libitum access to food (Standard feeds, standard rat pellets) and water, with $12 / 12 \mathrm{~h}$ day and night cycle at room temperature (20$\left.25{ }^{\circ} \mathrm{C}\right)$. All experiments were performed between 08:00 and 12:00 $\mathrm{h}$.

\section{Methods \\ Induction of Type 1 Diabetes Mellitus}

Type 1 diabetes mellitus was induced after two weeks acclimatization period; baseline blood glucose levels, and behavioural and cognitive assessments were performed for all test animals. This was done to ensure that the animals were all normoglycaemic with no anxiety, depression and had normal locomotive functions using the elevated plus maze (data not included).

Fifty eight male Wistar rats were randomly selected the sixty four rats and induced with $55 \mathrm{mg} / \mathrm{kg}$ of STZ in citrate buffer $(0.1 \mathrm{M}, \mathrm{pH} 4.5)$, while six normoglycaemic male Wistar rats was used as control. The solution was used within $5 \mathrm{~min}$ to induce diabetes in the rats after an overnight fast of $12 \mathrm{~h}$ (Godam et al. 2014).

\section{Hyperglycaemia Screening and Confirmation of T1DM}

Four days after STZ-induced diabetes mellitus, blood was collected from the tail vein following an overnight fast (Meiri et al. 1997; Walther et al. 1998; Kulkarni 1999). Fasting blood sugar was measured with a standard glucometer (Optimum, Germany). The day that hyperglycaemia (200 mg/dL; $11 \mathrm{mmol} / \mathrm{l})$ was confirmed was considered to be diabetic day 1. Rats with fasting blood glucose levels lower than 200 $\mathrm{mg} / \mathrm{dL}$ were excluded from the study.

\section{Animal Grouping and Treatment Procedure}

Forty eight diabetic rats and six normoglycaemic rats were randomly divided into nine groups as shown in the Table 1, and treated with melatonin and insulin intraperitoneally, and magnesium orally for twenty one days according to the bioactive compounds and drugs dosage assigned to each group. The controls were given distilled water. Melatonin and insulin were given intraperitoneally while magnesium was administered orally.

At the end of the study ( $24 \mathrm{~h}$ after last administration, day 21) animals where sacrificed humanely using ketamine as anaesthesia intraperitoneally at a dose of $0.8 \mathrm{mg} / \mathrm{kg}$. The rat brains were carefully removed cleared of any debris, weighed and washed in normal saline. They were further fixed in buffered formalin. 


\section{Histological and Histochemical Studies}

Tissue samples were harvested and fixed in $10 \%$ buffered formalin for $72 \mathrm{~h}$. The samples were grossed and labelled in tissues cassettes and processed for histology using varying concentration of alcohols (70, 80,90 and $100 \%$ ) for dehydration, cleared through three changes of toluene, infiltrated, embedded in molten paraffin wax and blocked on cold ice packs. The tissues were sectioned at $10 \mu \mathrm{m}$ using a rotary microtome (Leica, Germany) and the ribbons obtained were picked on clean grease free Leica charged slides for histological and immunohistochemical studies. The slides were drained and heat fixed on a hot plate at $70{ }^{\circ} \mathrm{C}$. The tissues were further dewaxed in toluene, hydrated in decreasing concentration of alcohol, and taken to water before proceeding to the staining procedures. Portions of the hippocampus were stained using H\&E methods for general histological studies (Suvarna et al. 2018).

\section{Table 1: Rats Grouping and Dosage}

\begin{tabular}{lll}
\hline Group & $\mathrm{n}$ & Treatment (21 days) \\
\hline NC & 6 & $2.0 \mathrm{~mL} / \mathrm{kg}$ distilled water \\
DC & 6 & $2.0 \mathrm{~mL} / \mathrm{kg}$ distilled water \\
MLD & 6 & $10 \mathrm{mg} / \mathrm{kg}$ melatonin \\
MgLD & 6 & $240 \mathrm{mg} / \mathrm{kg}$ magnesium \\
MMgLD & 6 & $10 \mathrm{mg} / \mathrm{kg}$ melatonin $240 \mathrm{mg} / \mathrm{kg}$ magnesium \\
MHD & 6 & $20 \mathrm{mg} / \mathrm{kg}$ melatonin \\
MgHD & 6 & $480 \mathrm{mg} / \mathrm{kg}$ magnesium \\
MMgHD & 6 & $20 \mathrm{mg} / \mathrm{kg}$ melatonin+480 $\mathrm{mg} / \mathrm{kg}$ magnesium \\
IN & 6 & Insulin $(500$ mg $/ \mathrm{kg})$ \\
\hline
\end{tabular}

NC (control), DC (Diabetic control), MLD (Melatonin low dose), MgLD (Magnesium low dose), MMgLD (Melatonin and magnesium low dose), MgHD (Magnesium high dose), MHD (Melatonin high dose), MMGHD (Melatonin and Magnesium high dose), IN (Insulin)

The immunohistochemical marker, glial fibrillary acidic protein (GFAP) was used to study hippocampal astrocytes. The representative sections on slides was pre-treated using heat mediated antigen retrieval in citrate buffer $(0.1 \mathrm{M}, \mathrm{pH} 6.0)$, placed in boiling bath for $90 \mathrm{~min}$. Endogenous peroxidase was blocked in 3\% hydrogen peroxide for $30 \mathrm{~min}$ and later blocked using serum (normal goat serum, C-0005) at $37^{\circ} \mathrm{C}$ for $20 \mathrm{~min}$.

It was further incubated with rabbits/mouse antiGFAP, unconjugated (GF5-ab10062) at 1:400 dilutions for $45 \mathrm{~min}$. It was later conjugated to the secondary antibody (SP-0023). It was later labelled with mouse/rabbit horseradish enzyme (DB Biotech, Slovakia) for $30 \mathrm{~min}$, and DAB (C-0010) for $10 \mathrm{~min}$. Then stained with haematoxylin for nuclear contrast, and mounted with DPX.
The photomicrographs of sections were obtained using Leica DM750 microscope with digital Camera ICC50E LAS EZ software installed in HP 8th gen Core i5 Laptop.

\section{RESULTS}

\section{Hippocampus Histology}

Sections of the hippocampus (CA1 area) were studied qualitatively using haematoxylin and eosin stains to characterize changes associated with STZ induced diabetes. Normal control administered distilled water showed similar normal cellular cytoarchitecture with pyramidal cells in the CA1 area of the hippocampus of the rats (Fig. 1A\&B).

The hippocampus of the STZ-induced diabetic control showed disorganized CA1 area with degenerated pyramidal cells and shrunken darkly stained nuclei, wide pericellular spaces and pyknosis (Fig. 1C\&D). Melatonin $(10 \mathrm{mg} / \mathrm{kg})$ treated rats showed restored hippocampal neurocytes with decreased pericellular spaces (Fig. 1E\&F). Magnesium $(240 \mathrm{mg} / \mathrm{kg}$ ) treated rats showed distorted cellular cytoarchitecture with wide pericellular spaces (Fig. 1G\&H).

Melatonin $(10 \mathrm{mg} / \mathrm{kg})$ + magnesium (240 mg/kg) treated rats showed restoration of neurocytes with less pericellular spaces and preservation of the cytoarchitecture (Fig. 1I\&J). Melatonin (20 mg/kg) showed distortions of cellular cytoarchitecture and loss of neuronal cells (Fig. 1K\&L). Magnesium (480 $\mathrm{mg} / \mathrm{kg}$ ) treated rats showed preservation of pyramidal cells and reduced cellular distortion with improved cytoarchitecture (Fig. 1M\&N). Melatonin $(20 \mathrm{mg} / \mathrm{kg})+$ magnesium $(480 \mathrm{mg} / \mathrm{kg})$ treated rats showed distortions of cellular cytoarchitecture and loss of neurocytes (Fig. 1O\&P). The insulin treated diabetic rats showing mild distortion of cellular cytoarchitecture and disorganization of neuronal cells (Fig. 1Q\&R).

\section{Hippocampus Astrocytes Study}

The normal control group showed normal GFAP positivity (Fig. 2A\&B). The diabetic control rats showed strong positive GFAP reaction with astrocytic inflammation (Fig. 2C\&D). The melatonin (10 mg/kg) treated rats showed less positive GFAP with no astrocytic inflammation (Fig. 2E\&F). The magnesium $(240 \mathrm{mg} / \mathrm{kg}$ ) treated rats showed strong GFAP positivity (Fig. 2G\&H). The melatonin $(10 \mathrm{mg} / \mathrm{kg})+$ magnesium $(240 \mathrm{mg} / \mathrm{kg})$ treated rats showed less GFAP positivity (Fig. 2I\&J). The melatonin $(20 \mathrm{mg} / \mathrm{kg}$ ) treated rats showed less GFAP positivity (Fig. 2K\&L). The magnesium $(480 \mathrm{mg} / \mathrm{kg})$ treated rats showed mild positive astrocyte reaction (Fig. 2M\&N). The melatonin $(20 \mathrm{mg} / \mathrm{kg})+$ magnesium $(480 \mathrm{mg} / \mathrm{kg})$ treated rats showed strong positive GFAP (Fig. 2O\&P). The insulin $(500 \mathrm{mg} / \mathrm{kg})$ treated rats showed strong GFAP positivity (Fig. 2Q\&R). 


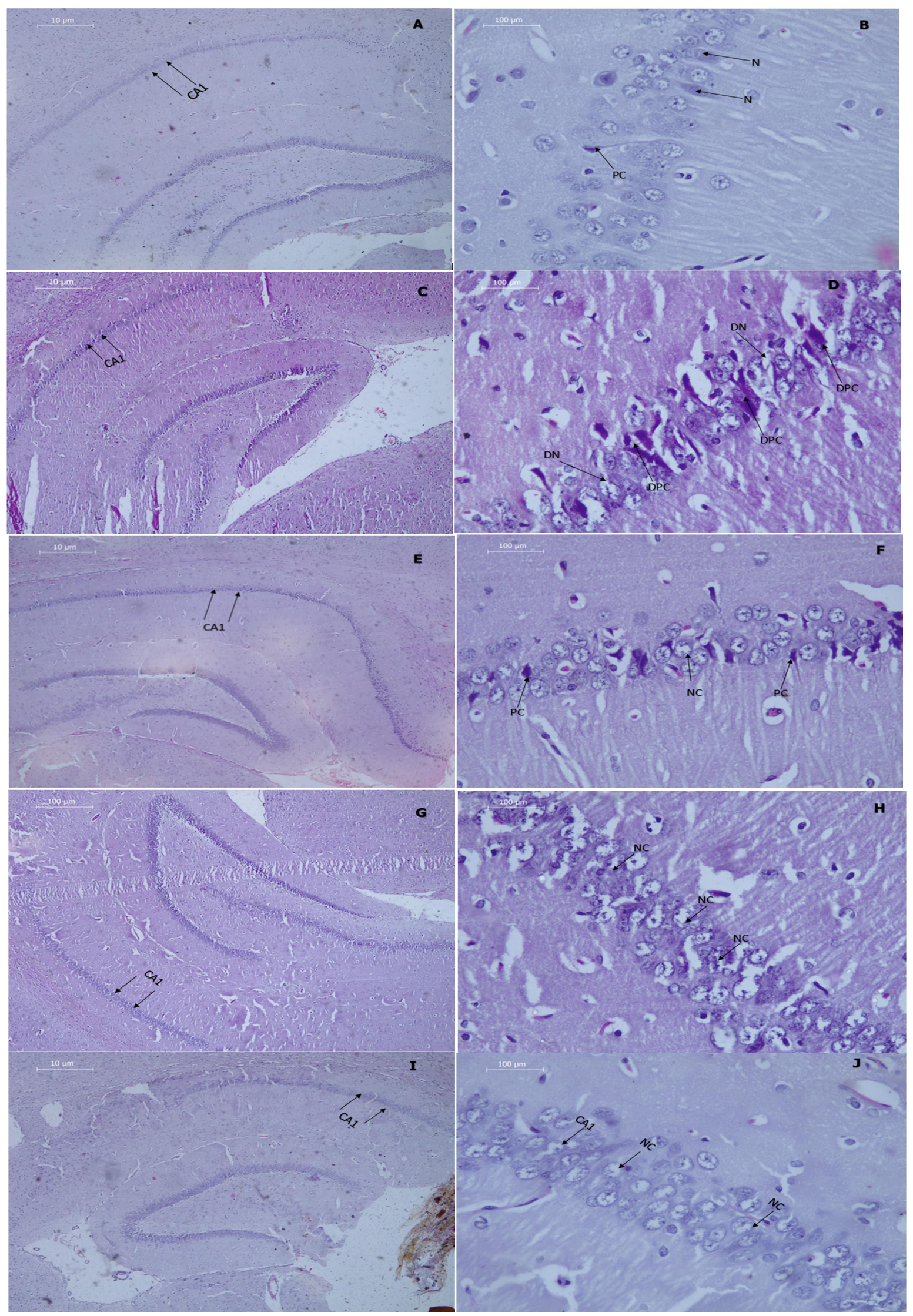




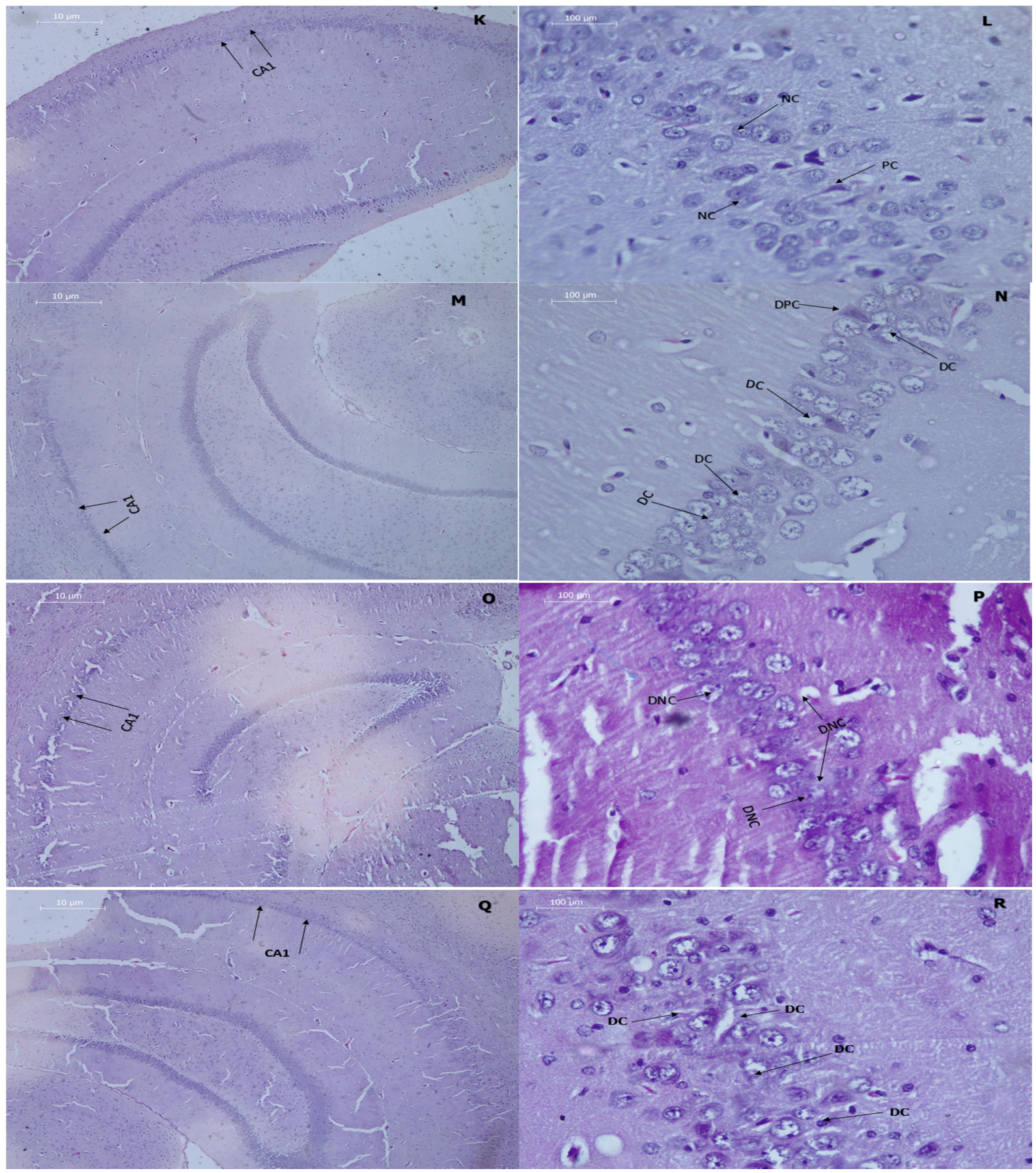

Fig. 1: Histological sections of the hippocampus (CA1) of rats (H\&E, ×400). A\&B: The control group with normal cytoarchitecture with pyramidal cells (black arrows). C\&D: Diabetic control rats showing distorted cytoarchitecture with disorganized neurocytes, degenerated pyramidal cells and shrunken darkly stained nuclei (black arrows). E\&F: Melatonin $(10 \mathrm{mg} / \mathrm{kg})$ treated rats showing restored pyramidal cells with decreased peri-cellular spaces. G\&H: Magnesium $(240 \mathrm{mg} / \mathrm{kg}$ ) treated rats showing distorted cellular cytoarchitecture with wide peri-cellular spaces. I\&J: Melatonin $(10 \mathrm{mg} / \mathrm{kg})+$ Magnesium $(240 \mathrm{mg} / \mathrm{kg})$ treated rats showing restoration of neurocytes, pyramidal cells with less peri-cellular spaces with preservation of the cytoarchitecture. K\&L: Melatonin $(20 \mathrm{mg} / \mathrm{kg}) \mathrm{showing}$ distortions of cellular cytoarchitecture and loss of neuronal cells (black arrows). M\&N: Magnesium (480 mg/kg) treated rats showing preservation of pyramidal cells and reduced cellular distortion with improved cytoarchitecture. O\&P: Melatonin (20 $\mathrm{mg} / \mathrm{kg})+$ magnesium $(480 \mathrm{mg} / \mathrm{kg})$ treated rats showing distortions of cellular cytoarchitecture and loss of neurocytes. Q\&R: Insulin $(500 \mathrm{mg} / \mathrm{kg})$ treated rats showing mild cytoarchitecture distortions and disorganizations of neuronal cells. 


\section{DISCUSSION}

The hippocampus is an area of the brain that is involved in short- and long- term memory (Eichenbaum 2004; Staresina and Davachi 2009; Fuentemilla et al. 2010; Poch et al. 2011). In rats, amnesia can be caused by hippocampal dysfunction (Lyeth et al. 1990), whereas in higher animals including primate's memory loss can occur due to dysfunctions in both the hippocampus and amygdala (Mishkin et al. 1978). Diabetes has been linked to memory impairment in rats (Sacai et al. 2014) and in humans (Gravlee et al. 2011). Hypoglycaemia on the other hand can also cause hippocampal injury which could result to anterograde amnesia. In this study, STZ was used to induced diabetes (sustained hyperglycaemia) which has been proven to induce oxidative stress in the hippocampus (Lee et al (2014) resulting in apoptosis of the hippocampal synapses (Zhang et al. 2013). Hippocampal oxidative stress is associated with increased level of lipid peroxidation products (Mushtag et al. 2014) and decreased activity levels of endogenous intracellular antioxidant in diabetic rats (Moghaddam et al. 2014). Hence, in this study, light microscopic results from the control group showed normal CA1 area cytoarchitecture with pyramidal cells, which the diabetic rats administered melatonin $(20 \mathrm{mg} / \mathrm{kg})$ and melatonin $(10 \mathrm{mg} / \mathrm{kg})+$ magnesium $(240 \mathrm{mg} / \mathrm{kg}$ ) showed similar organized and restored cellular cytoarchitecture and pyramidal cells. However, the diabetic control rats showed distorted cytoarchitecture with disorganized cells, degenerated pyramidal cells and shrunken darkly stained nuclei which the groups administered respectively, magnesium $(240 \mathrm{mg} / \mathrm{kg}$ and 480 $\mathrm{mg} / \mathrm{kg})$, melatonin $(20 \mathrm{mg} / \mathrm{kg})+$ magnesium (480 $\mathrm{mg} / \mathrm{kg}$ ), and insulin (500 mg/kg) were similar, with mild cytoarchitecture distortions and disorganizations of neuronal cells. Diabetes is associated with several adverse effects on the brain, some of which may result primarily from direct consequences of chronic hyperglycaemia (Amin et al. 2013).

Immunohistochemically, it was observed that the diabetic control group showed increased GFAP expression (strong positive expression), which showed neuroinflammation of astrocytes due to untreated diabetic hyperglycaemia. These findings are similar to the report by Sacli et al. (2015) which states that in vivo studies of STZ-induced diabetes increased blood-brain-barrier permeability with melatonin preventing the increase in blood brain barrier permeability. Melatonin inhibits matrix metalloproteinase- 9 expression and also protects against the loss of tight junction proteins and blood brain barrier disruptions by providing antiinflammatory and antioxidant mediators leading to axonal growth and regeneration. Astrocytes are proving critical for the survival of neurons in the central nervous system (CNS), playing a role in energy metabolism, maintenance of the blood-brain barrier, vascular reactivity, regulation of extracellular glutamate levels and protection from reactive oxygen species. This protect CNS cells through the uptake of excitotoxic glutamate, the production of the antioxidant glutathione and the neuroprotective adenosine (Swanson et al. 20004; Vargas at al. 2008; Chen et al. 2008). Alterations in astrocytes activity were associated with diabetes-related disturbances in the brain and levels of GFAP have been under debate (Baydas et al. 2003; Voskuhl et al. 2008).

Results from the normal control group in our study showed that there was normal GFAP expression in normal astrocytes. This result was similar to the melatonin treatment at $10 \mathrm{mg} / \mathrm{kg}, 20 \mathrm{mg} / \mathrm{kg}$ and when combined with magnesium $(240 \mathrm{mg} / \mathrm{kg})$ where we observed significant decrease in GFAP positive expression. The magnesium treated groups at 240 $\mathrm{mg} / \mathrm{kg}, 480 \mathrm{mg} / \mathrm{kg}$ and at high dose with $20 \mathrm{mg} / \mathrm{kg}$ melatonin showed positive expression of GFAP for astrocytes. The insulin treated group showed positive GFAP expression indicating astrocytic inflammation A report by Zhang et al. (2013) collaborates with our present findings; they demonstrated that diabetes cause debilitating changes in the hippocampus and that these changes contributed to neuronal loss. Histological findings by Lee et al. (2014), Duarte et al. (2009) and Giribabu et al. (2014) confirms our reports and previous reports of neurodegenerative changes in the hippocampus of diabetic rats. They observed histopathological necrotic changes in the Cornu Ammonis (CA) and subiculum areas of hippocampus with severe loss of pyramidal neurons and glial cells. It also collaborates with earlier results by $\mathrm{Li}$ et al. (2002) who reported that diabetic neuronal degeneration was due to apoptosis induced by oxidative changes due to hyperglycaemia. In our present findings, melatonin and magnesium at low dose reverses this neuronal degeneration and decreased GFAP expression with normal glial cells population in the hippocampus. There was no evidence of significant astrogliosis in melatonin and melatonin and magnesium co-treated diabetic groups.

Our report supports findings by Baydas et al. (2003) who reported that GFAP was significantly elevated in the diabetic control group compared to control group. These findings showed that untreated type 1 diabetes induced glial hyperactivity with increased GFAP in the rats' hippocampus. Baydas and colleagues attributed this to the effect of reactive oxygen species especially because oxidative stress occurs earlier in type 1 diabetes (Hoeldtke et al. 2003).

Moreover, Lebed et al. (2008) assessed GFAP for three and seven days after STZ injection using immunohistochemistry, and demonstrated that the reduced GFAP-positive cell count was found on day 3 when these cells were significantly smaller and less arborized with respect to the control. This tendency 

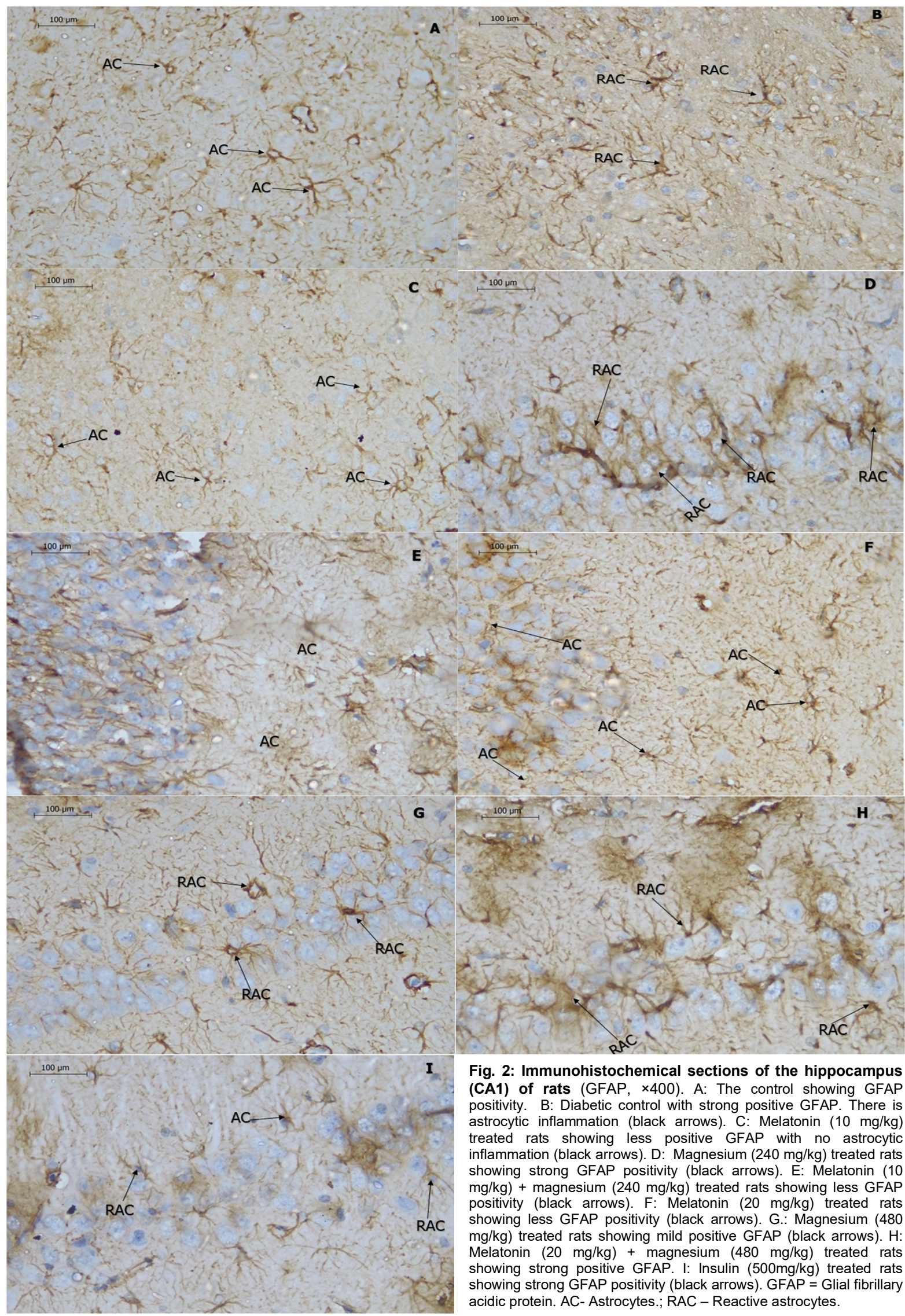

Fig. 2: Immunohistochemical sections of the hippocampus (CA1) of rats (GFAP, $\times 400$ ). A: The control showing GFAP positivity. B: Diabetic control with strong positive GFAP. There is astrocytic inflammation (black arrows). C: Melatonin $(10 \mathrm{mg} / \mathrm{kg})$ treated rats showing less positive GFAP with no astrocytic inflammation (black arrows). D: Magnesium $(240 \mathrm{mg} / \mathrm{kg}$ ) treated rats showing strong GFAP positivity (black arrows). E: Melatonin (10 $\mathrm{mg} / \mathrm{kg})+$ magnesium $(240 \mathrm{mg} / \mathrm{kg})$ treated rats showing less GFAP positivity (black arrows). F: Melatonin $(20 \mathrm{mg} / \mathrm{kg})$ treated rats showing less GFAP positivity (black arrows). G.: Magnesium (480 $\mathrm{mg} / \mathrm{kg}$ ) treated rats showing mild positive GFAP (black arrows). $\mathrm{H}$ : Melatonin $(20 \mathrm{mg} / \mathrm{kg})+$ magnesium $(480 \mathrm{mg} / \mathrm{kg})$ treated rats showing strong positive GFAP. I: Insulin $(500 \mathrm{mg} / \mathrm{kg})$ treated rats showing strong GFAP positivity (black arrows). GFAP = Glial fibrillary acidic protein. AC- Astrocytes.; RAC - Reactive astrocytes. 
reversed on day 7 when more numerous GFAPpositive cells grew in size and became more ramified. Insulin in the type 1 group significantly decreased hippocampal GFAP compared to the diabetic and normal control groups. These results agree with that of Lechuga-Sancho et al. (2006), but contradict that of Coleman et al. (2010). At the end of our study (21 days of melatonin and low dose magnesium treatment) we found out that melatonin reduces astrogliosis and neuroinflammation caused by hyperglycaemia induced type 1 diabetes mellitus, improving memory and cognition in diabetic rats.

\section{Conclusion}

Melatonin administration at $10 \mathrm{mg} / \mathrm{kg}, 20 \mathrm{mg} / \mathrm{kg}$ and when $10 \mathrm{mg} / \mathrm{kg}$ melatonin was co-administration with $240 \mathrm{mg} / \mathrm{kg}$ magnesium ameliorates and restores hippocampal astrocytic cells inflammations; preventing diabetic encephalopathy in STZ-induced diabetic rats.

\section{Conflict of Interest \\ None declared}

\section{REFERENCES}

Adeghate, E., Schattner, P. and Dunn, E. (2006) An update on the etiology and epidemiology of diabetes mellitus. Annual New York Academic Science Journal. 1084:1-29.

Alvarez, E.O., Beauquis, J., Revsin Y., Banzan, A.M., Roig. P. and De Nicola, A.F. (2009) Cognitive dysfunction and hippocampal changes in experimental type-1 diabetes. Behavioral Brain Research Journal. 198(1):224-230.

Amin, S.N., Younan, S.M., Youssef, M.F., Rashed, L.A. and Mohamady I.A. (2013) A histological and functional study on hippocampal formation of normal and diabetic rats. F1000 Research. 2:151. https://doi.org/10.12688/f1000research.2-151.v1.

Baydas, G., Netzeviiski, V.S. and Tuscu, M. (2003) Increase of glial fibrillary acidic protein and S-100B in hippocampus and cortex of diabetic rats: effects of vitamin E. European Journal of Pharmacology, 462(1-3):67-71.

Brands, A.M., Biessels, G.J., De Haan, E.H., Kappelle, L.J. and Kessels, R.P. (2005) The effects of type 1 diabetes on cognitive performance: a metaanalysis. Diabetes Care Journal. 28(3):726-735.

Bytzer, P., Talley, N.J., Leemon, M., Young, L.J., Jones, M.P. and Horowitz, M. (2001) Prevalence of gastrointestinal symptoms associated with diabetes mellitus: a population-based survey of 15,000 adults. Archives of Internal Medicine Journal. 161:19891996.

Chen, S.H, Lin, J.K. and Liu, S.H. (2008) Apoptosis of cultured astrocytes induced by the copper and neocuproine complex through oxidative stress and
JNK activation. Toxicology Science Journal. 102(1): 138-149.

Coleman, E.S., Dennis, J.C. and Braden, T.D. (2010) Insulin treatment prevents diabetes induced alterations in astrocyte glutamate uptake and GFAP content in rats at 4 and 8 weeks of diabetes duration. Brain Research Journal. 1306:131-141.

Duarte, C.G. (2009) Effects of chlorothiazide and amipramizide (MK 870) on the renal excretion of calcium, phosphate and magnesium. Journal of Metabolism. 17:420-429.

Eichenbaum, H. (2004) Hippocampus: cognitive processes and neural representations that underlie declarative memory. Neuron Journal. 44(1):109-120. Fuentemilla, L., Penny, W.D., Cashdollar, N., Bunzeck, N. and Düzel, E. (2010) Theta-coupled periodic replay in working memory. Current Biological Science Journal. 20:607-612 doi:10.1016/j.cub.2010. 01.057.

Giribabu, N., Srinivasarao, N., Somesula, S.R., Muniandy, S. and Salleh, N, (2014) Centella asiatica attenuates diabetes induced hippocampal changes in experimental diabetic rats. Evidence-Based Complementary and Alternative Medicine 2014: 592062. http://dx.doi.org/10.1155/2014/592062

Godam, E.T., Samaila, M.O.A., Ibegbu, A.O., Hamman, W.O. and Musa, S.A. (2014) Hypoglycaemic effects of melatonin and ethanol extract of Azadirachta indica administration on blood glucose levels in streptozotocin-induced diabetic Wistar rats. Annals of Experimental Biology Journal. 2(3):58-62.

Gravlee, J.R. and Barrett, J.J. (2011) Transient global amnesia in a collegiate baseball player with type I diabetes mellitus: a case report. Journal of Athletic Training. 46(3)319-321.

Hoeldtke, R.D., Bryner, K.D. and McNeill, D.R. (2003) Oxidative stress and insulin requirements in patients with recent-onset type 1 diabetes. Journal of Clinical Endocrinology Metabolism. 88(4):1624-1628.

Koistinaho, M., Lin, S. and Wu, X. (2004) Apolipoprotein $\mathrm{E}$ promotes astrocyte localization and degradation of deposited amyloid-beta peptides. Nature Medical Journal. 10(7):719-726.

Kuhad, A. and Chopra, K. (2007) Curcumin attenuate diabetic encephalopathy in rats Behavioral and biochemical evidences. European Journal of Pharmacology. 576(1-3):34-42.

Kulkarni, S.K. (1999) Hand Book of Experimental Pharmacology. 3rd ed. Vallabh Prakash: Delhi. 8589.

Lebed, Y.V., Orlovsky, M.A. and Nikonenko, A.G. (2008) Early reaction of astroglial cells in rat hippocampus to streptozotocin-induced diabetes. Neuroscience Letters Journal. 444(2):181-185.

Lechuga-Sancho, A.M., Arroba, A.I. and Frago, L.M. (2006) Reduction in the number of astrocytes and their projections is associated with increased synaptic protein density in the hypothalamus of poorly 
controlled diabetic rats. Endocrinology Journal. 147(11):5314-5324.

Lee, B.H., Lee, C.C. and Wu, S.U. (2014) Ice plant (Mesembryanthemum crystallinum) improves hyperglycaemia and memory impairments in a Wistar rat model of streptozotocin-induced diabetes. Journal of the Science of Food and Agriculture. 94(11):22662273.

Li, R., Zang, A., Zhang, L., Zhang, H., Zhao, L. and Qi, Z. (2014) Chrysin ameliorates diabetesassociated cognitive deficits in wistar rats. Neurology Science Journal. 35:1527-1532.

Lyeth, B.G., Jenkins, L.W. and Hamm, R.J, (1990) Prolonged memory impairment in the absence of hippocampal cell death following traumatic brain injury in the rat. Brain Research Journal. 526(2):249258.

Meiri, N., Chelardini, C., Tesco, G., Galeotti, N., Dahl, D. and Tomsic, D. (1997) Reversible antisense inhibition of Shaker-like Kv1.1 potassium channel expression impairs associative memory in mouse and rat. ProcNational Academic Science Journal. 94(9):4430-4434.

Mishkin, M. (1978) Memory in monkeys severely impaired by combined but not by separate removal of amygdala and hippocampus. Nature. 273:297-298.

Moghaddam, H.K., Baluchnejadmojarad, T. Roghani, M, Khakshri M., Norouzi P., Ahooie, M., et al. (2014) Berberine ameliorate oxidative stress and astrogliosis in the hippocampus of STZ-induced diabetic rats. Molecular Neurobiology. 49(2): 820-826.

Mushtag, N., Schmatz, R.L.B. and Pereira, L.N. (2014) Rosmarinic acid prevents lipid peroxidation and increase in acetylcholinesterase activity in brain of streptozotocin-induced diabetic rats. Cell Biochemistry and Function Journal. 32(3):287-293.

Poch, C., Fuentemilla, L., Barnes, G.R. and Düzel, E. (2011) Hippocampal theta-phase modulation of replay correlates with configural-relational short-term memory performance. Journal of Neuroscience. 31:7038-7042 1523/jneurosci.630510.2011.

Ramanathan, M., Jaiswal, A.K. and Bhattacharya, S.K. (1998) Differential effects of diazepam on anxiety in streptozotocin induced diabetic and nondiabetic rats. Psychopharmacology Journal of Berlin. 135(4):361-367.

Ricci, J.A., Siddique, R., Stewart, W.F., Sandler, R.S., Sloan, S. and Farup, C.E. (2000) Upper gastrointestinal symptoms in a U.S. national sample of adults with diabetes. Scandinavian Journal of Gastroenterology. 35:152-159.
Ryan, C.M. and Williams, T.M. (1993) Effects of insulin-dependent diabetes on learning and memory efficiency in adults. Journal of Clinical Experimental Neuropsychology. 15(5):685-700.

Sacai, H., Sasaki-Hamada, S., Sugiyama, A., Saitoh, A., Mori, K., Yamaga, M., et al. (2014) The impairment in spatial learning and hippocampal LTD induced through the PKA pathway in juvenile-onset diabetes rats are rescued by modulating NMDA receptor function. Neuroscience Research. 81-82:5563.

Sima, A.A., Zhang, W., Muzik, O., Kreipke, C.W., Rafols, J.A. and Hoffman, W.H. (2009) Sequential abnormalities in type 1 diabetic encephalopathy and the effects of C-Peptide. Revised Diabetic Studies Journal. 6(3):211-222.

Staresina, B.P. and Davachi, L. (2009) Mind the gap: binding experiences across space and time in the human hippocampus. Neuron Journal, 63:267-276 10.1016/j.neuron.2009.06.024.

Swanson, R.A., Ying, W. and Kauppinen, T.M. (2004) Astrocyte influences on ischemic neuronal death. Current Molecular Medicine Journal. 4(2):193-205.

Thorre, K., Chaoulof, F., Sarre, S., Meeusen, R., Ebinger, G. and Michotte, Y. (1997) Differential effects of restraint stress on hippocampal 5-HT metabolism and extracellular levels of $5-\mathrm{HT}$ in streptozotocin-diabetic rats. Brain Research Journal. 772(1-2):209-216.

Vargas, M.R., Johnson, D.A. and Sirkis, D.W. (2008) Nrf2 activation in astrocytes protects against neurodegeneration in mouse models of familial amyotrophic lateral sclerosis. Journal of Neuroscience. 28(50):13574-13581.

Voskuhl, R.R., Peterson, R.S., Song, B., Ao, Y., Morales, L.B., Tiwari-Woodruff, S. and Sofroniew, M.V. (2009) Reactive astrocytes form scar-like perivascular barriers to leukocytes during adaptive immune inflammation of the CNS. Journal of Neuroscience, 29(37):11511-11522.

Walther, T., Balschun, D., Voigt, J.P., Fink, H., Zuschratter, W. and Birchmeier, C. (1998) Sustained long term potentiation and anxiety in mice lacking the Mas proto-oncogene. Journal of Biology and Chemistry., 273(19):11867-11873.

Zhang, Y.C., Pileggi, A., Agarwal, A., Molano, R.D., Powers, M., Brusko, T., et al. (2003) Adenoassociated virus-mediated IL-10 gene therapy inhibits diabetes recurrence in syngeneic islet cell transplantation of NOD mice. Diabetes Journal. 52: 708-716.

Cite as Godam, E.T., Hamman, W.O., Oladele, S., Samaila, M.O. and Musa, S.A. (2020) Melatonin and magnesium restores neurohistopathological changes in the hippocampus of streptozotocin-induced diabetic rats. Nig. J. Neurosci. 11(2):71-79. http://doi.org/10.47081/njn2020.11.2/003 